\title{
A retrospective analysis on placenta previa in a tertiary care center of Jharkhand
}

\author{
Tanu Sharma* \\ Department of Obstetrics and Gynecology, PJMCH, Dumka, Jharkhand, India
}

Received: 18 July 2021

Accepted: 09 August 2021

\author{
*Correspondence: \\ Dr. Tanu Sharma, \\ E-mail: tanisha.anu@gmail.com
}

Copyright: $\odot$ the author(s), publisher and licensee Medip Academy. This is an open-access article distributed under the terms of the Creative Commons Attribution Non-Commercial License, which permits unrestricted non-commercial use, distribution, and reproduction in any medium, provided the original work is properly cited.

\begin{abstract}
Background: When the placenta is implanted partially or completely in the lower uterine segment, it is called placenta previa. Previa is a Latin word means going before. About one-third of APH belongs to placenta previa and now a day's incidence is increasing in primigravida patients. The objective of this study was to analyze the incidence, risk factors, maternal morbidity, mortality and perinatal outcome in women with placenta previa in a tertiary care center of Jharkhand.

Methods: Total 193 cases of placenta previa were studied between September 2018 to August 2019 in the department of obstetrics and gynecology, RIMS, Ranchi with respect to their age, parity, gestational age, clinical presentation, previous history of curettage/hysterotomy/caesarean, ICU admission, need for NICU admission, maternal morbidity and mortality and perinatal outcome.

Results: In this study, $1.94 \%$ of the deliveries were complicated with placenta previa. $31.6 \%$ were above 30 years, $87 \%$ were multigravida, 122 , i.e.; $62.7 \%$ were having history of curettage or previous caesarean or hysterotomy. $49.7 \%$ had prior caesarean deliveries, $21.5 \%$ had prior abortion with history of D and C. $49.2 \%$ had true placenta previa. $68.4 \%$ had preterm delivery. $11.9 \%$ patients presented in shock and maximum i.e.; $184(95.3 \%)$ out of 193 presented with painless bleeding per vaginum and 9 cases with no complaints. Malpresentation seen in $16.6 \%$ cases and $8.3 \%$ had adherent placenta previa. There were $45.6 \%$ ICU admission and 54.9\% NICU admission, $2.5 \%$ maternal mortality and $32.6 \%$ perinatal mortality.

Conclusions: Advanced maternal age, multiparty, scarred uterus as in prior CS or D and C are independent risk factors for placenta previa. Also, it remains a risk factor for adverse maternal and perinatal outcome. The detection of placenta previa and associated adherent placenta should encourage a careful evaluation, timely diagnosis and delivery to reduce associated maternal and perinatal complications.
\end{abstract}

Keywords: Placenta previa, Adherent placenta, Maternal morbidity and mortality

\section{INTRODUCTION}

When the placenta is implanted partially or completely in the lower uterine segment it is called placenta previa. It is responsible for $1 / 3$ of $\mathrm{APH}$ cases and its incidence is $0.3 \% .^{1}$ The classical feature is sudden, painless, causeless and recurrent bleeding pervaginum, usually seen after $2^{\text {nd }}$ trimester. Sentinel bleed is usually seen which is rarely profuse and not so fatal. ${ }^{1}$ There are multiple predisposing factors among which the most important is previous uterine scar like previous history of curettage, hysterotomy and previous cesearean. ${ }^{2}$ Incidence is $2.2 \%$ in previous 1 , $4.1 \%$ in previous 2 and $22.4 \%$ in previous 3 or more cesarean. ${ }^{3}$ Other causes are advanced maternal age, seen 9 fold greater in pregnancies $>40$ years than in $<20$ years of age. ${ }^{2}$ Large placenta in multiparity, multiple pregnancy and smoking leading to enchroachment of placental edge in lower segment.

Types of placenta previa (according to ACOG, NIH)- (a) true placenta previa- covers the internal os; (b) low lying placenta previa - lies within $2 \mathrm{~cm}$ of internal os. 
Sonography is the simplest and safest technique for the diagnosis. TVS is more precise than TAS in localization of placental edge. ${ }^{3}$

There is increased incidence of antepartum hemorrhage leading to shock and its consequences, increased incidence of operative interventions, increased incidence of postpartum hemorrhage, need of ICU facility and blood transfusion, all posing increased risk of maternal morbidity and mortality. It alone accounts for nearly $3 \%$ of maternal death due to hemorrhage. ${ }^{1}$

Fetal morbidity is mainly because of iatrogenic prematurity. The overall perinatal mortality rate is $4-8 \%{ }^{3}$

Management of placenta previa depends on gestational age, presentation, type of previa, maternal and fetal condition. ${ }^{7,9}$ Expectant management is McAfee regimen indicated in cases with stable vitals, mild bleeding/ spotting $\mathrm{p} / \mathrm{v}$, preterm and with reassuring FHR, therefore, it can improve the outcome. ${ }^{10}$ RCOG recommends cesarean delivery for women with placental edge within 2 cm circumference of internal os. ${ }^{3}$

The likelihood of morbidly adherent placenta is more in prior uterine incision and if the placenta is implanted anteriorily, the need for hysterectomy increases. Atonic PPH or bleeding from placental bed not controlled by conservative management also pose more risk for hysterectomy. ${ }^{1}$

The objective of this study was to determine the incidence, demographic features, obstetric risk factors, obstetric management, maternal mortality and morbidity and perinatal outcome in women presenting with placenta previa.

\section{METHODS}

This was a retrospective observational study conducted at Rajendra Institute of Medical Sciences in the department of obstetrics and gynaecology between September 2018 to August 2019. All 193 women with gestational age beyond 24 weeks and who were diagnosed with placenta previa at or after admission were included in the study.

Parameters like age, parity, gestational age, clinical presentation, history of present pregnancy and previous pregnancies, complications, need for ICU admission, number of blood transfusion, need for ventilatory support, causes of mortality, expectant management, PPH and surgical interventions like cervico-isthmic sutures, Blynch sutures, uterine artery ligation or peripartum hysterectomy and perinatal outcome in terms of gestational age, rate of stillbirth, malpresentation, presence of congenital anomaly, prematurity, need for NICU admission and perinatal mortality etc were noted.

Data was obtained from labour room records and medical record department and analyzed. Pregnant women who went LAMA were excluded from the study. Permission was taken from the ethical committee of the institute.

\section{RESULTS}

During the study period, there were 9952 deliveries, of which, 193, i.e.; $1.94 \%$ were complicated with placenta previa.

The age distribution of present study group is shown in Table 1 . Nearly one fourth of women were above 30 years of age.

In the present study there are $25(13 \%)$ primigravida, 56 (29\%) second gravidas, $55(28.5 \%)$ third gravidas, 34 $(17.6 \%)$ fourth gravidas, $16(8.3 \%)$ fifth gravida, $2(1 \%)$ sixth gravida, $3(1.5 \%)$ seventh and $1(0.5 \%)$ ninth and tenth gravida each. More than three fourth of women $(87 \%)$ in this study were multigravidas.

$148(76.7 \%)$ cases were un-booked and 154 (79.8\%) came with ultrasonography report documenting placenta previa, in which 14 were adherent placenta previa.

Type of placenta previa depending on the location (diagnosed either by ultrasound or during cesarean delivery) is shown in Table 2. There were 93 (49.2\%) cases of true placenta previa in the present study.

$184(95.4 \%)$ admitted with history of bleeding per vaginum out of which $23(11.9 \%)$ were in shock. $56(29 \%)$ with severe anemia and $9(4.6 \%)$ with no complaints as shown in Figure 1.

In the present study there were $63(32.6 \%)$ cases with previous 1 cesarean delivery, $31(16.1 \%)$ with prior 2 cesarean, $1(0.5 \%)$ with previous 3 cesarean and 21 $(10.8 \%)$ with history of prior abortion and D and C.

$77(39.8 \%)$ of the cases which is about one third were seen in unscarred uterus in which mostly were multiparous and more than 30 years of age. This being depicted in Figure 2.

$61(31.6 \%)$ cases were term and 132 (68.4\%) were preterm. All cases were delivered by cesarean section.

There were $36(18.6 \%)$ cases of postpartum hemorrhage. As shown in Table 3, 2.6\% cases managed by cervicoisthmic stitches, $9.8 \%$ by B-lynch stitches and $5.2 \%$ by uterine artery ligation. 7.2\% Cases underwent emergency peripartum hysterectomy when bleeding could not be controlled by conservative methods. $16(8.3 \%)$ cases of adherent placenta and $12(6.2 \%)$ underwent peripartum hysterectomy while 4 cases managed conservatively by leaving placenta followed by methotrexate therapy with serial Beta-hCG and ultrasonography monitoring.

$9(4.7 \%)$ of women were managed by McAfee and Johnson regimen, which includes bed rest, blood 
investigation, blood cross-matching, watch for vaginal bleeding, ultrasonography and steroid prophylaxis if gestational age less than 34 weeks. 36 (18.6\%) had postpartum hemorrhage and $16(8.3 \%)$ had adherent placenta.

All (100\%) patients require blood transfusion, 79 (40.9\%) required massive transfusion of blood and blood products. There were 88 (45.6\%) ICU admissions, 8 (4.1\%) needed ventilatory support. 5 cases died out of which 4 due to $\mathrm{PPH}$ and 1 due to DIC. As shown in Table 4, 132 (68.4\%) babies were preterm and 106 (54.9\%) needed NICU admission. $39(20.2 \%)$ were stillborn with $1(0.5 \%)$ having congenital anomaly (amelia).

Malpresentation seen in $32(16.6 \%)$ cases in which maximum were breech and few in transverse lie.

Table 1: Age distribution.

\begin{tabular}{|lll|}
\hline Age (years) & $\begin{array}{l}\text { Number } \\
(\mathbf{N}=193)\end{array}$ & $\begin{array}{l}\text { Percentage } \\
(\%)\end{array}$ \\
\hline$<\mathbf{2 0}$ & 16 & 8.3 \\
\hline $\mathbf{2 0 - 2 4}$ & 48 & 24.8 \\
\hline $\mathbf{2 5 - 2 9}$ & 73 & 37.9 \\
\hline $\mathbf{3 0}$ and above & 56 & 29 \\
\hline
\end{tabular}

Table 2: Type of placenta previa (by USG and intraoperative findings).

\begin{tabular}{|lll|}
\hline Types (by ACOG, NIH) & $\begin{array}{l}\text { Number } \\
(\mathbf{N}=193)\end{array}$ & $\begin{array}{l}\text { Percentage } \\
(\%)\end{array}$ \\
\hline True placenta previa & 93 & 49.2 \\
\hline Low lying placenta previa & 100 & 51.8 \\
\hline
\end{tabular}

Table 3: Additional surgical procedures/maneuvers done.

\begin{tabular}{|lll|}
\hline Types of procedures & $\begin{array}{l}\text { Number } \\
(\mathbf{N}=\mathbf{1 9 3})\end{array}$ & $\begin{array}{l}\text { Percentage } \\
(\%)\end{array}$ \\
\hline Cervico-isthmic sutures & 05 & 2.6 \\
\hline B-lynch suture & 19 & 9.8 \\
\hline Uterine artery ligation & 10 & 5.2 \\
\hline $\begin{array}{l}\text { Emergency peripartum } \\
\text { hysterectomy }\end{array}$ & 12 & 6.2 \\
\hline $\begin{array}{l}\text { Uterine artery ligation f/b } \\
\text { hysterectomy }\end{array}$ & 02 & 01 \\
\hline
\end{tabular}

Table 4: Neonatal outcome.

\begin{tabular}{|lll|}
\hline Factors & $\begin{array}{l}\text { Number } \\
(\mathbf{N = 1 9 3})\end{array}$ & $\begin{array}{l}\text { Percentage } \\
(\%)\end{array}$ \\
\hline Preterm birth & 132 & 68.4 \\
\hline NICU admission & 106 & 54.9 \\
\hline Still birth & 39 & 20.2 \\
\hline Malpresentation & 32 & 16.6 \\
\hline Early neonatal death & 24 & 12.4 \\
\hline Congenital anomaly & 01 & 0.5 \\
\hline
\end{tabular}

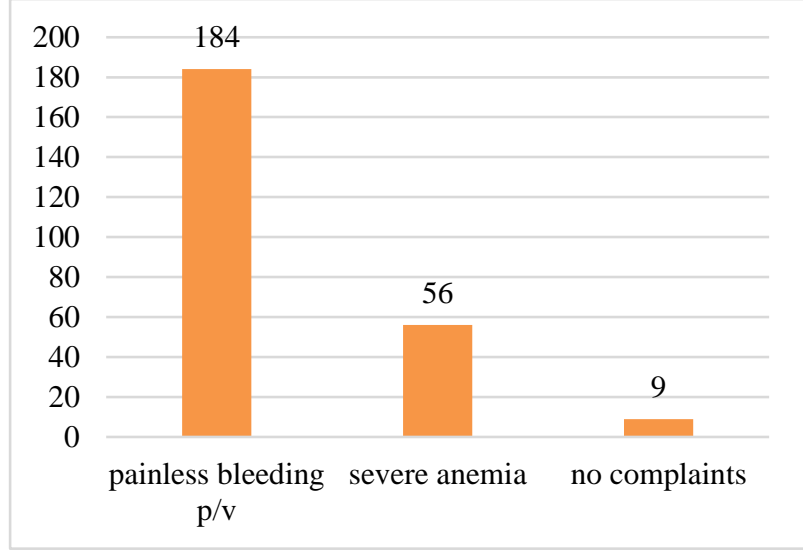

Figure 1: Clinical presentation.

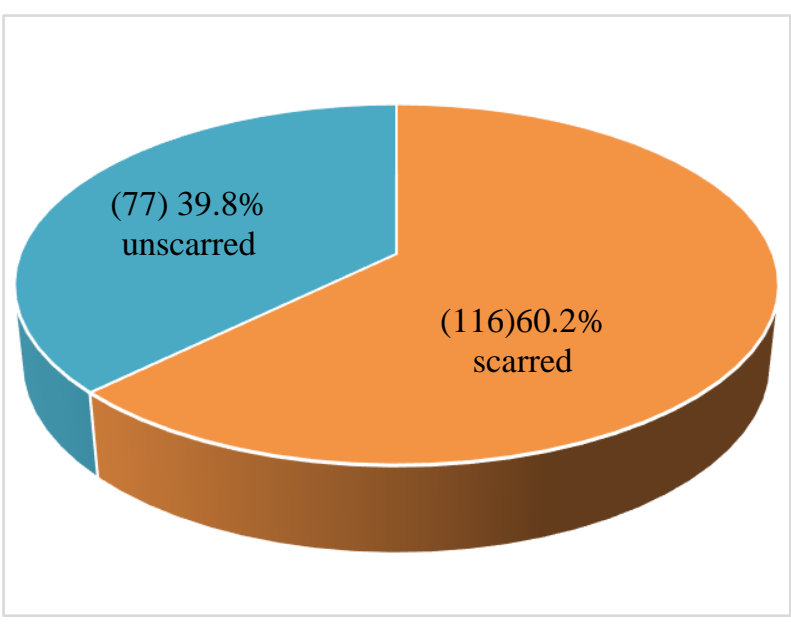

Figure 2: Causes/risk factors.

\section{DISCUSSION}

Placenta previa was one of the dreaded complications in obstetrics due to high associated maternal and perinatal morbidity and mortality. The incidence seen in present study was $1.94 \%$ which was almost similar to study by Bhatt et al. ${ }^{8}$ Advancing age and multiparity have been shown to be an important risk factor for placenta previa. In terms of parity $87 \%$ were multigravida which is supported by Shivananjaiah et al and Ojha et al in their studies. ${ }^{6,10}$ $37.9 \%$ cases were between 25-30 years which is comparable to study by Shivananjaiah et al. ${ }^{10}$

According to NIH and ACOG classification, almost half cases had true placenta previa which was similar with the study by Daskalakis et al. ${ }^{9}$

Scarred uterus was one of the independent cause of placenta previa and in present study, $60.2 \%$ cases had history of previous cesarean or previous D and E which was comparable to the study done by Shivananjaiha et al and slightly more than the study done by Ojha et al. ${ }^{6,10}$ Here $8.3 \%$ patients had adherent placenta. In present study 95.3\% cases underwent cesarean section, results are comparable to studies conducted by Rangaswamy et al and 
Daskalakis et al being $95.2 \%$ and $93.9 \%$ respectively. ${ }^{9,11}$ $4.7 \%$ cases were managed by expectant management and all had better maternal and fetal outcome. In present study, only $31.6 \%$ patients were $>37$ weeks of gestational age, which was very less than the studies done by Ojha et al and Shivananjaiha et al. ${ }^{6,10}$ Thus, in present study most were preterm $(68.4 \%)$, so the incidence of NICU admission of babies were more.

Regarding maternal morbidity, $18.6 \%$ had PPH, which was almost similar to the study done by Rangaswamy et al and Bhatt et al where incidence were $16.1 \%$ and $17 \%$ respectively. ${ }^{8,11} 100 \%$ patient needed blood transfusion which is same as in Rangaswamy study. ${ }^{11}$ Hysterectomy done in $7.2 \%$ cases which was almost double of the incidence reported by Rangaswamy et al and Shivananjaiha et al. ${ }^{10,11}$ Its incidence was very less in Ojha et al study and very high in Daskalakis et al study. ${ }^{6,9}$ The incidence of hysterectomy was high due to atonic PPH cannot be managed by serial devascularization or due to morbidly adherent placenta. $45.6 \%$ patients needed ICU support and $4.1 \%$ were put on ventilator.

Regarding neonatal outcome, $16.6 \%$ had malpresentation which was almost comparable to the study by Ojha et al $(21.4 \%){ }^{6} 68.4 \%$ babies were pre-term, $20.2 \%$ were stillborn which was 5 times of Bhatt et al study, mainly due to late presentation, ignorance of the patients and late referral. $^{8} 1$ had congenital anomaly. Early neonatal death seen in $12.4 \%$ cases which is almost same as in Ojha et al and almost half of the incidence reported by Bhatt et al study. ${ }^{6,8}$ Morbidity was more in preterm babies as depicted in various studies on perinatal outcome in the cases of placenta previa. There was decrease in NICU admission rate in babies born in advanced gestational age in present study as supported by the study done by Rosenberg et al. ${ }^{5}$ Maternal mortality was $2.6 \%$ in present study and this is equal to the maternal mortality reported by Bhatt et al in his study. Maximum patient died due to PPH followed by shock.

\section{CONCLUSION}

Advanced maternal age, multiparity, prior cesarean section and history of curettage are the important risk factors for placenta previa. An increase in the incidence of risk factors contributes to the increase rate of placenta previa. Placenta previa is a dreadful maternal complication adversely affects the maternal and perinatal outcome. The management should depend on clinical presentation, severity of bleeding, gestational age and type of placenta previa. But an obstetrician should be very vigilant and careful regarding decision for termination of pregnancy as expectant management can increase the chance of survival in neonates and decrease the incidence of perinatal morbidity and mortality due to prematurity. Thus, its early detection, a careful evaluation and timely delivery should be encouraged for better fetomaternal outcome.

\section{Funding: No funding sources}

Conflict of interest: None declared

Ethical approval: The study was approved by the Institutional Ethics Committee

\section{REFERENCES}

1. Cunningham FG, Leveno KJ, Bloom SL, Haulh JC, Gilstrap LC, Wenstrom KD. Obstetrics hemorrhage. Williams Textbook of Obstetrics. 25th ed. New York, NY: McGraw-Hill; 2005: 773-777.

2. Gupta B, Misra R. Antepartum Hemorrhage. Ian Donald's Practical Obstetric Problems. 7th ed. India: Wolters Kluwer; 2015: 315-323.

3. Arias F, Bhide AG, Arulkumaran S, Damania K, Daftary SN. Arias' Practical Guide to high risk pregnancy and delivery. 4th ed. India: Elsevier; 2019: 151-155.

4. Onwere C, Urganci I, Cromwell DA, Mahmood TA, Templeton A, Meulen JH. Maternal morbidity associated with placenta praevia among women who had elective caesarean section. Eur J Obstet Gynecol Reprod Biol. 2011;159(1):62-6.

5. Rosenberg T, Pariente G, Sergienko R, Wiznitzer A, Sheiner E. Critical analysis of risk factors and outcome of placenta previa. Arch Gynecol Obstet. 2011;284(1):47-51.

6. Ojha N. Obstetric factors and pregnancy outcome in placenta previa. J Institute Med. 2012;34:38-41.

7. Gargari S, Seify Z, Haghighi L, Khoshnood SM, Mirzamoradi M. Risk Factors and Consequent Outcomes of Placenta Previa: Report From a Referral Center. Acta Med Iran. 2016 ;54(11):713-7.

8. Bhatt AD, Meena A, Desai MR. Maternal and perinatal outcome in cases of Placenta previa. Int J Sci Res. 2014;3(1):299-301.

9. Daskalakis G, Simou M, Zacharakis D, Detorakis S, Akrivos N, Papantoniou N, et al. Impact of placenta previa on obstetric outcome. Int J Gynaecol Obstet. 2011;114(3):238-41.

10. Shivananjaiha $C$, Malapure P. Maternal and neonatal outcome in placenta previa and adherent placenta: a retrospective study in a tertiary care center. The New Indian J Obstet Gynecol. 2018;4(2);150-2.

11. Rangaswamy M, Govindaraju K. Fetomaternal outcome in placenta previa- a retrospective study in teaching hospital. Int $\mathbf{J}$ Reprod Contracept Obstet Gynecol. 2016;5:3081-4.

Cite this article as: Sharma T. A retrospective analysis on placenta previa in a tertiary care center of Jharkhand. Int J Reprod Contracept Obstet Gynecol 2021;10:3389-92. 